Acta Technologica Agriculturae 4

Nitra, Slovaca Universitas Agriculturae Nitriae, 2019, pp. 115-121

\title{
THE EFFECT OF TRACTOR DRIVING SYSTEM TYPE ON ITS SLIP AND ROLLING RESISTANCE AND ITS MODELLING USING ANFIS
}

\author{
Abdolmajid MOINAR, Gholamhossein SHAHGHOLI* \\ University of Mohaghegh Ardabili, Iran
}

\begin{abstract}
Pulling force required for operations such as tillage is a result of the interaction between the tractor's wheel drive and soil surface limited by various factors, such as the rolling resistance and slip of the wheel drive. In this research, the traction performance of tractors with different driving systems (four-wheel drive, rear wheel drive, and front wheel drive) was investigated. Test parameters included different tractor forward speeds $\left(1.26,3.96\right.$, and $\left.6.78 \mathrm{~km} \cdot \mathrm{h}^{-1}\right)$, tire inflation pressures $(170,200$, and $230 \mathrm{kPa})$, ballast weights $(0,150$, and $300 \mathrm{~kg})$, and aforementioned driving systems, as well as required drafts $(2,6$, and $10 \mathrm{kN})$. For each experiment, two indices of slip and rolling resistance were measured. The results of this study showed that the four-wheel-driving system indicated a low slip at similar pulling forces. In order to achieve a low slip, the four-wheel driving system did not necessarily need to add the ballast weight or to reduce the inflation pressure. The four-wheel driving system showed lower rolling resistance than the other two systems. Slip and rolling resistance of wheels were predicted using an adaptive neuro-fuzzy inference system (ANFIS). It was found that ANFIS had a high potential for predicting the slip $\left(R^{2}=0.997\right)$ and rolling resistance $\left(R^{2}=0.9893\right)$.
\end{abstract}

Keywords: motion system; ballast weight; tractor performance; inflation pressure

The optimum criterion for evaluating the tractor performance is calculation of the tractor traction performance during ploughing operations on soft soils (Battiato and Diserens, 2017). The pulling force required for operations such as tillage is a result of the interaction between the tractor's wheel drive and soil surface, which converts the power generated by the engine to the pulling force. Majority of studies have shown that 20 to $55 \%$ of tractor power is lost in the process of interaction between tire and soil surface due to the drive wheel slip, tractor's rolling resistance, and tire and soil deformation (Damanauskas and Janulevicius, 2015). The tractive performance is affected by the tractor design parameters, attaching tools, and soil conditions (Moinfar and Shahgholi, 2018).

If the wheel drive slip exceeds $15 \%$, it will result in severe soil compaction and reduced performance (Moitzi et al., 2013). Slipping less than $7 \%$ during agricultural operations can be achieved by deployment of very heavy tractors. However, in this case, carrying excessive weights leads to increased fuel consumption and soil compaction, which are considered undesirable (Janulevicius et al., 2018).

Main factors affecting the rolling resistance of a pneumatic tire in deformable soils are soil displacement, tire flexibility, and soil friction and adhesion; several other subfactors are wheel diameter, inflation pressure, and axle load. Research shows that the wheel diameter has an indirect relationship, the axle load has a direct relationship, and the inflation pressure has an inverse relationship with the rolling resistance (Elwaleed et al., 2006). When the soil is hard, its cohesion is high, leading to less slipping and lower rolling resistance (Moitzi et al., 2013), while in plastic state, soil cohesion decreases and adhesion to tire increases. This causes higher tire sinking, making the wheels slip, and high rolling resistance, resulting in greater loss of power and reduced tractor efficiency (Battiato et al., 2013).

Considering the tillage operation, it has been reported that, depending on the amount of ballast weight and its location, the draft can be increased up to 15\% (Muhsin, 2010). However, this method has an adverse effect on soil and causes soil compaction in a depth that is usually deeper than that of conventional tillage operations (Barbosa and Magalhaes, 2015). The excess ballast weight also increases fuel consumption due to increased rolling resistance and higher tire sinkage in the soil. On the other hand, when the ballast weight is lower than optimal value, tractor will waste fuel due to excessive slipping (Lacour et al., 2014). Another way to reduce the slip is to increase the contact surface between the drive wheel and soil surface. By reducing the tire pressure, contact surface can be increased (Battiato and Diserens, 2013) or it can be used with double wheels (Damanauskas et al., 2015), both of which increase the area of the wheel contact with the soil.

In recent years, artificial intelligence techniques have been developed to model complex and uncertain systems. An efficient example of these techniques is the integration of artificial neural network (ANN) and fuzzy inference system. Fuzzy logic performs the inference mechanism with uncertainty in recognition while the ANN also has the ability to learn, adapt, and process in parallel. The hybrid system is called Adaptive Neuro-Fuzzy Interference System

Contact address: Gholamhossein Shahgholi, University of Mohaghegh Ardabili, Faculty of Agriculture and Natural Resources, Department of Biosystem Engineering, Ardabil, Iran, e-mail: gshahgoli@yahoo.com 
(ANFIS) (Buckley and Hayashi, 1994). This method can solve complex issues relying on learning capabilities and parallel processing capabilities in ANNs. In terms of fuzzy systems, an approximate decision-making process is based on individual or group human experience. In these systems, the quantitative modelling is performed qualitatively and intuitively (instead of using quantitative values) and thus it is necessary to deal with indeterminants (Wang, 1997). Nevertheless, these systems do not have the ability to learn and, in confrontation with the complex systems, the regulation of membership functions and required rules are time-consuming and difficult. Although the ability of fuzzy systems has been approved in solving of complex problems related to modelling and prediction, control, and artificial intelligence (Wang, 1997), given the complementary (rather competitive) capabilities of these two solutions, it is possible to simultaneously use their advantages by combining them. In a research conducted by Taghavifar and Mardani (2014), authors predicted energy efficiency indicators using ANFIS. Input parameters included wheel load, speed, and slip, each of them at three levels. The results of this study showed a high prediction accuracy (MSE $=0.0166$ and $R^{2}=0.98$ ). Ghadernejad et al. (2018) conducted a study to predict soil compaction under tractor wheels, utilizing the ANFIS model with four inputs: manure, number of passes, moisture, and depth. The results of this study showed a higher accuracy in predicting soil density than the regression model.

The objective of this study is to evaluate the tractor performance indices (slip and rolling resistance) in frontwheel-drive, rear-wheel-drive, and four-wheel-drive modes. Furthermore, ANFIS models were designed to predict tractor slip and rolling resistance in different tractor configurations, taking into account ballast weights, tire inflation pressure, various travel speeds of the tractor, and different required drafts.

\section{Material and methods}

Field tests were conducted at the Research Farm of Ardabil Agricultural Research Center ( $38^{\circ} 12^{\prime} 46.6^{\prime \prime} \mathrm{N}, 48^{\circ} 17^{\prime} 42.2^{\prime \prime} \mathrm{E}$, and $1,350 \mathrm{~m}$ above sea level). The field was flat and had common barley (Hordeum vulgare Linnaeus) stubble residues from the previous season. Soil texture was loamy clay. Moisture and other soil properties were measured in 30 randomly selected points within the whole field at two depths: 0-25 and 25-50 cm. Results are presented in Table 1. Observed parameters included different levels of tractor forward speed $\left(1.26,3.96\right.$, and $\left.6.78 \mathrm{~km} \cdot \mathrm{h}^{-1}\right)$, tire inflation pressure $(170,200$, and $230 \mathrm{kPa})$, ballast weights $(0,150$, and $300 \mathrm{~kg}$ ), tractor motion systems (front-wheel-drive, rear-wheel-drive, and four-wheel-drive), and pulling force $(2,6$, and $10 \mathrm{kN})$ for each experiment, on the basis of which two indices of slip and rolling resistance were measured. Type of motion system is not a numerical property, yet the modelling requires numerical values. In this regard, the tractor-implement system slip can represent an appropriate index of driving system type. In order to incorporate the effect of the driving system to the modelling process, the tractor slip value in different motion systems was used.
Table 1 Physical properties of the field soil

\begin{tabular}{|c|c|}
\hline Property & Value \\
\hline Sand (\%) & 40 \\
\hline Silt (\%) & 28 \\
\hline Clay (\%) & 32 \\
\hline Organic matter $\left(\mathrm{g} \cdot 100 \mathrm{~g}^{-1}\right)$ & 0.29 \\
\hline Plastic limit & 25.76 \\
\hline Liquid limit & 39.81 \\
\hline Plasticity index & 14.05 \\
\hline (\%) Field capacity based on dry weight & 10.13 \\
\hline Dry bulk density $(0-25 \mathrm{~cm})\left(\mathrm{g} \cdot \mathrm{cm}^{-3}\right)$ & 1.35 \\
\hline Dry bulk density $(25-50 \mathrm{~cm})\left(\mathrm{g} \cdot \mathrm{cm}^{-3}\right)$ & 1.46 \\
\hline Moisture content based on dry weight (\%) $(0-25 \mathrm{~cm})$ & 9.3 \\
\hline Moisture content based on dry weight (\%) $(25-50 \mathrm{~cm})$ & 10.4 \\
\hline
\end{tabular}

Technical characteristics of the Goldoni 240 tractor (4WD) used for testing are presented in Table 2. The front and rear tractor differentials related to the driving system were alternately disabled for the experiments, so the tractor could operate either as having front or rear wheel drive system. A subsoiler was used to create draft. Variation in the draft was obtained by changing the depth of subsoiler operation. Drafts of 2, 6 and $10 \mathrm{kN}$ were obtained using a subsoiler tine at a depth of $30 \mathrm{~cm}$, two subsoiler tines at a depth of $30 \mathrm{~cm}$ and two subsoiler tines at a depth of $50 \mathrm{~cm}$, respectively. To measure the rolling resistance, the Goldoni 240 tractor in unloaded mode was towed by another tractor and the force required to move the Goldoni 240 tractor was measured using load cell installed between the two tractors. The draft applied to the tractor was measured using a threepoint connecting dynamometer (Abbaspour-Gilandeh and Haghighat-Shishvan, 2011). The variation in the measured draft was in the range of $\pm 0.05 \mathrm{~N}$.

Table 2 Tractor characteristics

\begin{tabular}{|l||c|c|}
\hline Specifications & Unit & Value \\
\hline \hline Type of tractor engine & - & $\begin{array}{c}\text { Diesel (3 } \\
\text { Cylinders) }\end{array}$ \\
\hline Engine power & $(\mathrm{kW})$ & 30.8 \\
\hline Static weight on front tires & $(\mathrm{kg})$ & 705 \\
\hline Static weight on rear tires & $(\mathrm{kg})$ & 360 \\
\hline
\end{tabular}

The tractor wheel speed was measured utilizing an inductive proximity sensor mounted in line with the outer edge of a 34-tooth sprocket fixed inside the rear wheel (Fig. 1). Inductive proximity sensor is a non-contact device that is set up on a radio frequency field with an oscillator and a coil. Presence of a metal object (tooth) changes the field and the sensor detects the change. The resolution is $0.0003 \mathrm{~m} \cdot \mathrm{s}^{-1}$. The sensor detected passing of each tooth during the wheel rotation so that with each full rotation of the gear or rear wheel, digital display of pulse meter attached to a magnetic sensor displayed the number of gear teeth. This number was divided by 34 to calculate the wheel rotation. 


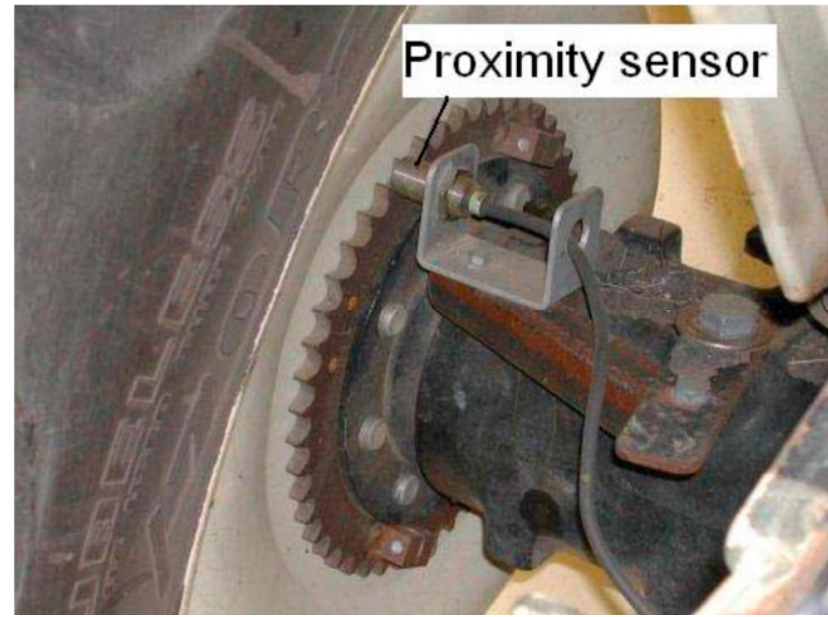

Fig. 1 Wheel speed transducer for measuring of tire rotation

Distance travelled was calculated by having a perimeter of the rear wheel. Dynamic rolling radius was determined and considered in computing rear wheel perimeter. The actual speed of the tractor was easily computed by measuring the time required to travel this distance using a stopwatch. The following Eq. (1) was used to calculate the slip:

$$
\operatorname{Slip}(\%)=1-\frac{v_{a}}{v_{t}} \cdot 100
$$

where:

$v_{a} \quad-$ actual velocity $\left(\mathrm{m} \cdot \mathrm{s}^{-1}\right)$

$v_{t} \quad-$ theoretical velocity $\left(\mathrm{m} \cdot \mathrm{s}^{-1}\right)$

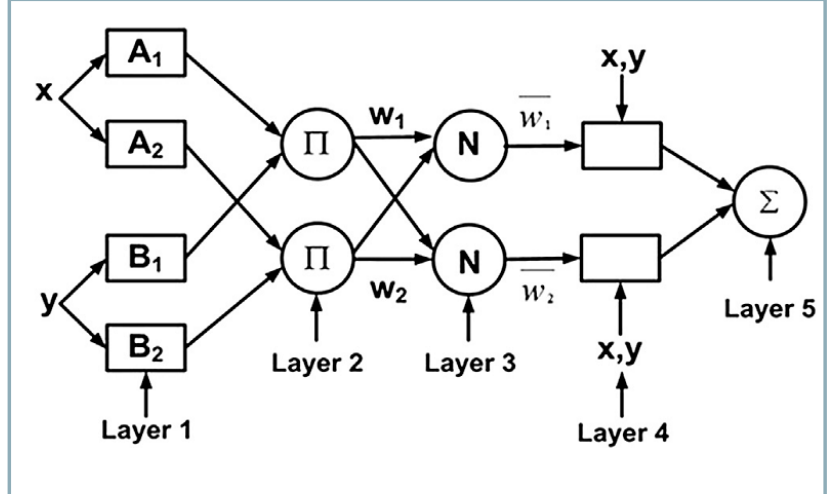

Fig. 2 Basic structure of the Adaptive Neural-Fuzzy Inference System (ANFIS)

\section{Adaptive neuro-fuzzy inference system}

ANFIS is a multi-layer adaptive network consisting of main elements and functions of fuzzy logic systems. In general, the ANFIS system consists of a 5-layer structure with a number of input variables, each of which has two or more membership functions. Fig. 2 shows the ANFIS network architecture with two inputs, one output, and two rules.

In this study, two models for predicting slip and rolling resistance were developed in ANFIS. The first model is based on 5 input factors including inflation pressure, ballast weight, pulling force, tractor driving system, and forward speed. The second model is based on four input factors including inflation pressure, ballast weight, tractor driving system, and forward speed. Grid partition structure was used to create the network. Four common types of triangular, trapezoidal,

Table 3 Selected rules in the slip prediction model

\begin{tabular}{|c|c|c|c|c|c|c|}
\hline \multirow[t]{2}{*}{ Rules } & \multicolumn{5}{|c|}{ Input variables } & \multirow[t]{2}{*}{ Linear output function (\% slip) } \\
\hline & $\mathrm{D}$ & MS & $\mathrm{IP}$ & BW & $\mathrm{S}$ & \\
\hline 1 & $\mathrm{~L}$ & L & $\mathrm{L}$ & L & $\mathrm{L}$ & Slip $=1.28 \mathrm{D}+1.477 \mathrm{MS}+0.02369 \mathrm{IP}+0.006237 \mathrm{BW}+0.4499 \mathrm{~S}-2.768$ \\
\hline 5 & $\mathrm{~L}$ & L & $\mathrm{H}$ & L & $\mathrm{L}$ & Slip $=-0.02834 \mathrm{D}+0.1137 \mathrm{MS}+0.02552 \mathrm{IP}-0.0121 \mathrm{BW}-0.271 \mathrm{~S}+2.046$ \\
\hline 17 & $\mathrm{H}$ & $\mathrm{L}$ & $\mathrm{L}$ & $\mathrm{L}$ & $\mathrm{L}$ & Slip $=0.4836 \mathrm{D}+2.121 \mathrm{MS}+0.03794 \mathrm{IP}+0.04143 \mathrm{BW}+0.4147 \mathrm{~S}+0.7349$ \\
\hline 21 & $\mathrm{H}$ & L & $\mathrm{H}$ & L & $\mathrm{L}$ & Slip $=-1.277 \mathrm{D}+4.096 \mathrm{MS}+0.1376 \mathrm{IP}-0.01722 \mathrm{BW}+0.2468 \mathrm{~S}-0.5424$ \\
\hline 25 & $\mathrm{H}$ & $\mathrm{H}$ & $\mathrm{L}$ & L & $\mathrm{L}$ & Slip $=0.03331 \mathrm{D}-2.112 \mathrm{MS}+0.2052 \mathrm{IP}+0.06992 \mathrm{BW}+0.3297 \mathrm{~S}-0.1642$ \\
\hline 32 & $\mathrm{H}$ & $\mathrm{H}$ & $\mathrm{H}$ & $\mathrm{H}$ & $\mathrm{H}$ & Slip $=-0.4357 D-2.77 M S+0.1043 I P+0.03969 B W-0.1946 S+0.0002872$ \\
\hline
\end{tabular}

D - draft; MS - motion system; BW - ballast weight; IP - inflation pressure; S - speed

Table 4 Selected rules in the motion resistance prediction model

\begin{tabular}{|l||c|c|c|c|c|}
\hline \multirow{2}{*}{ Rules } & \multicolumn{4}{|c|}{ Input variables } & Linear output function (rolling resistance) \\
\cline { 2 - 5 } & MS & IP & BW & S & \\
\hline $\mathbf{1}$ & L & L & L & L & MR $=0.3103 \mathrm{MS}+0.002011 \mathrm{IP}+0.00459 \mathrm{BW}+0.01378 \mathrm{~S}-0.005265$ \\
\hline $\mathbf{2}$ & L & L & L & H & MR $=0.2182 \mathrm{MS}+0.00149 \mathrm{IP}+0.003894 \mathrm{BW}+0.02285 \mathrm{~S}+0.006151$ \\
\hline $\mathbf{5}$ & L & H & L & L & MR $=0.1141 \mathrm{MS}+0.003541 \mathrm{IP}-0.0004052 \mathrm{BW}-0.02053 \mathrm{~S}+0.003915$ \\
\hline $\mathbf{1 0}$ & H & L & L & H & MR $=-0.1223 \mathrm{MS}+0.006777 \mathrm{IP}+0.003032 \mathrm{BW}+0.04878 \mathrm{~S}+0.0007311$ \\
\hline $\mathbf{1 4}$ & H & H & L & H & MR $=-0.119 \mathrm{MS}+0.008611 \mathrm{IP}+0.003029 \mathrm{BW}-0.02972 \mathrm{~S}-0.0004734$ \\
\hline $\mathbf{1 6}$ & H & H & H & H & MR $=-0.08654 \mathrm{MS}+0.003808 \mathrm{IP}+0.004001 \mathrm{BW}+0.02254 \mathrm{~S}+2.343 \mathrm{e}-05$ \\
\hline
\end{tabular}

D - draft; MS - motion system; BW - ballast weight; IP - inflation pressure; S - speed 
Gaussian, and generalized-bell membership functions were considered for representing inputs. The number of membership functions for each input was considered to be the minimum possible value of 2 to prevent the creation of high rules and excessive system complexity. The input membership function used in this network is the linear type. The hybrid optimization method was used for network learning. The number of rules created by the network for slip and rolling resistance models is 32 and 16, respectively. Since the number of rules created is so high, there are presented only a few of them for a better understanding of ANFIS modelling (Tables 3 and 4). These rules were based on the fuzzy type Takagi-Sugeno-Kang (TSK). In this system, the foreground (if-then) is represented by fuzzy rules, but the resultant part is non-fuzzy and is a linear combination of input variables. The range of all inputs was divided into two parts: the low and the high areas, which were represented by the membership functions $L$ and $H$, respectively.

According to the weight of each rule, the final output value of the model was calculated by averaging the predicted values by the linear functions of each rule. The weight of each rule was equal to the minimum degree of membership of the inputs of its rule. Finally, the final output of the model was calculated from the following Eq. (2).

$$
f=\frac{w_{1} f_{1}+w_{2} f_{2}}{w_{1}+w_{2}}
$$

where:

$f_{1}, f_{2}$ - linear functions related to rules 1 and 2, respectively $w_{1}, w_{2}-$ weights corresponding with each rule

To evaluate the ability of developed models, two statistical measures of relative error $(\varepsilon)$ and coefficient of determination $\left(R^{2}\right)$ were used. These were given by Eqs. (3) and (4) (Carman, 2008):

$$
\begin{gathered}
\varepsilon=\frac{100}{N} \sum_{i=1}^{N} \frac{Y_{\text {measured }}-Y_{\text {predicted }}}{Y_{\text {measured }}} \\
R^{2}=\frac{\sum_{i=1}^{N}\left(Y_{\text {measured }}-Y_{\text {predicted }}\right)^{2}}{\sum_{i=1}^{N}\left(Y_{\text {measured }}-Y_{\text {mean }}\right)^{2}}
\end{gathered}
$$

where:

$Y_{\text {measured }} Y_{\text {predicted }}$ - measured and predicted values, respectively

$Y_{\text {mean }}$ - average value of all measured data

Furthermore, in this research, several multiple linear regression models were prepared in SPSS software to gain more knowledge on the effect of each input variable on the slip and rolling resistance.

\section{Results and discussion}

Tables 5 and 6 present the structural parameters of the models and their statistical measures for evaluating their performance. The results (Tables 5 and 6 ) show the high predictive power $\left(R^{2} \geq 0.99\right.$ and $\left.\varepsilon(\%) \leq 4\right)$ of all models. The best model for predicting slip uses triangular-shaped membership function (Trimf) with $R^{2}=0.997$ and $\varepsilon=3.08 \%$. The best model for prediction of the rolling resistance is the one that uses the generalized bell-shaped membership function (Gbellmf) with $R^{2}=0.9893$ and $\varepsilon=1.89 \%$.

Tables 7 and 8 present the statistical characteristics of the stepwise regression model for predicting slip and rolling resistance, respectively. The statistical models of slip prediction had $R^{2}=0.867$ and $\varepsilon(\%)=19$, and the rolling resistance prediction had $R^{2}=0.958$ and $\varepsilon(\%)=5$. According to the statistical factors, ANFIS models presented high accuracy in predicting the tractor slip and its rolling resistance. However, in comparison to the ANFIS models,

Table 5 The characteristics of the best structure of developed ANFIS architectures for slip; the bolded values show outperforming models

\begin{tabular}{|l||c|c|c|c|c|c|c|}
\hline \multirow{2}{*}{ Model } & \multicolumn{2}{|c|}{ Type of MF } & \multicolumn{2}{c|}{ Number of MF } & Optimization & \multicolumn{2}{|c|}{ Test } \\
\cline { 2 - 9 } & Input & Output & Input & Epoch & method & $\varepsilon(\%)$ & $\boldsymbol{R}^{\mathbf{2}}$ \\
\hline \hline Grid Partition & Trimf & Linear & 2222 & 20 & Hybrid & 3.08 & 0.997 \\
\hline Grid Partition & Gaussmf & Linear & 22222 & 20 & Hybrid & 3.31 & 0.997 \\
\hline Grid Partition & Trapmf & Linear & 22222 & 20 & Hybrid & 3.24 & 0.997 \\
\hline Grid Partition & Gbellmf & Linear & 22222 & 20 & Hybrid & 3.67 & 0.996 \\
\hline
\end{tabular}

\begin{tabular}{|c|c|c|c|c|c|c|c|}
\hline \multirow[t]{2}{*}{ Model } & \multicolumn{2}{|c|}{ Type of MF } & \multicolumn{2}{|c|}{ Number of MF } & \multirow{2}{*}{$\begin{array}{l}\text { Optimization } \\
\text { method }\end{array}$} & \multicolumn{2}{|c|}{ Test } \\
\hline & Input & Output & Input & Epoch & & $\varepsilon(\%)$ & $R^{2}$ \\
\hline Grid Partition & Trimf & Linear & 2222 & 20 & Hybrid & 2.69 & 0.9808 \\
\hline Grid Partition & Gaussmf & Linear & 2222 & 20 & Hybrid & 2.16 & 0.9871 \\
\hline Grid Partition & Trapmf & Linear & 2222 & 20 & Hybrid & 2.26 & 0.9866 \\
\hline Grid Partition & Gbellmf & Linear & 2222 & 20 & Hybrid & 1.89 & 0.9893 \\
\hline
\end{tabular}

Table 6 The characteristics of the best structure of developed ANFIS architectures for rolling resistance; the bolded values show outperforming models 
regression models have invaluable benefits. The regression model directly deals with the impact of each factor and it tries to provide a model, in which the importance and impact of each of the factors is clearly evident. In respect to the standard coefficients listed in Table 7, draft, tractor driving system, inflation pressure, ballast weight, and travel speed showed the greatest effect on the slip, in the presented order. Moreover, in respect to the standard coefficients

Table 7 Statistical characteristics of stepwise regression model for slip

\begin{tabular}{|l||c|c|c|c|c|}
\hline \multirow{2}{*}{ Model } & \multicolumn{2}{|c|}{ Unstandardized coefficients } & \multicolumn{3}{c|}{ Standardized coefficients } \\
\cline { 2 - 6 } & B & Std. error & Beta & $\boldsymbol{t}$ & sig \\
\hline \hline (Constant) & -15.474 & 1.644 & & -9.413 & 0.000 \\
\hline D & 1.622 & 0.056 & 0.689 & 29.126 & 0.000 \\
\hline MS & 4.330 & 0.223 & 0.460 & 19.436 & 0.000 \\
\hline IP & 0.083 & 0.007 & 0.263 & 11.129 & 0.000 \\
\hline BW & -0.016 & 0.001 & -0.257 & -10.847 & 0.000 \\
\hline S & -0.734 & 0.81 & -0.215 & -9.089 & 0.000 \\
\hline
\end{tabular}

Table 8 Statistical characteristics of stepwise regression model for rolling resistance

\begin{tabular}{|l||c|c|c|c|c|}
\hline \multirow{2}{*}{ Model } & \multicolumn{1}{|c|}{ Unstandardized coefficients } & \multicolumn{3}{c|}{ Standardized coefficients } \\
\cline { 2 - 6 } & B & Std. error & Beta & t & sig \\
\hline \hline (Constant) & -0.545 & 0.069 & & -7.909 & 0.000 \\
\hline MS & 0.327 & 0.010 & 0.788 & 34.338 & 0.000 \\
\hline BW & 0.001 & 0.000 & 0.451 & 19.674 & 0.000 \\
\hline IP & 0.005 & 0.000 & 0.358 & 15.604 & 0.000 \\
\hline S & -0.014 & 0.003 & -0.090 & -3.933 & 0.000 \\
\hline
\end{tabular}

Constant is $y$-intercept in a linear function
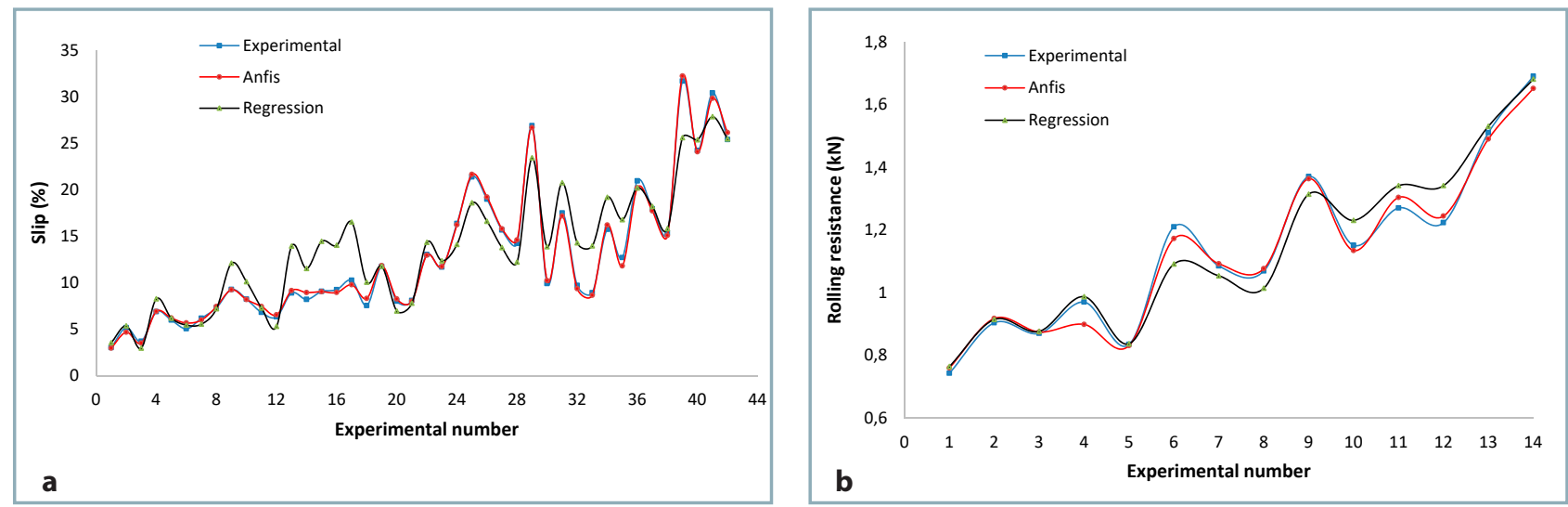

Fig. 3 Comparison of the values predicted by regression and ANFIS models with the observed values for (a) slip, (b) rolling resistance
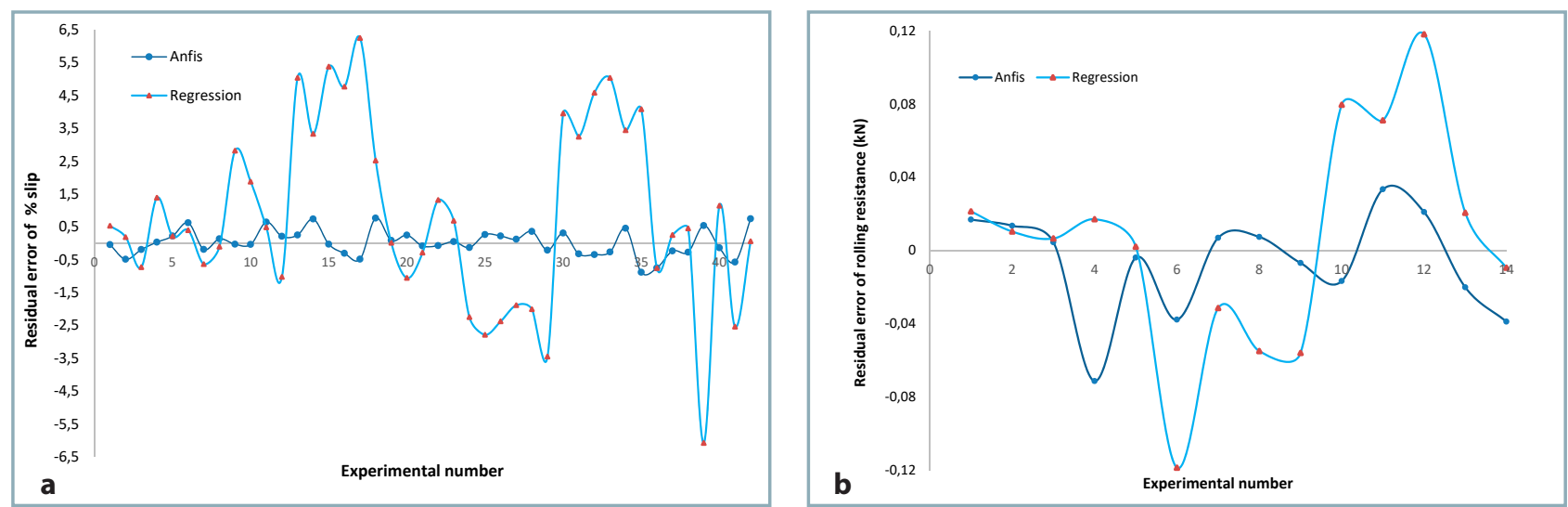

Fig. 4 Variation of the values predicted by regression and ANFIS models from the observed values for (a) slip, (b) rolling resistance 
listed in Table 8, the tractor driving system, ballast weights, inflation pressure, and tractor speed had the greatest impact on the rolling resistance, in the presented order.

Figs. $3 \mathrm{a}$ and $3 \mathrm{~b}$ illustrate the mapping between the experimental and predicted values for slip and rolling resistance by the ANFIS and stepwise regression models. Clearly, in contrast to the regression model, the ANFIS model provides a more accurate mapping of the experimental and predicted values. In addition to this, the deviation between the measured values and predicted values of the models were calculated and plotted. Figs. $4 \mathrm{a}$ and $4 \mathrm{~b}$ show that the standard deviation for the predicted values of the ANFIS model for slip (-0.88 to 0.76$)$ and the rolling resistance $(-0.033$ to 0.071$)$ are much lower than the deviation of the predicted values of the stepwise regression models for slip (-6.08 to 6.24) and rolling resistance (-0.118 to 0.1186$)$.

\section{Investigation of slip and rolling resistance as a result of the application of experimental factors}

The 3D surface curves of slip and rolling resistance as two indicators of the drive wheel performance are shown in Figs. 5 and 6, respectively. As it is clear from Fig. 5a, slip increases with increasing draft, but the use of four-wheel-drive mode makes it possible to achieve the maximum draft of $10 \mathrm{kN}$ at a relatively low slip level of $12.4 \%$, while when in the front- wheel-drive mode, this pulling force was achieved at a high slip level of $25.5 \%$. Many studies have reported that draft was the most important factor in terms of increasing the slip and optimal and economical slipping is recommended in the range of 10-15\% (Battiato and Diserens, 2013; Lacour et al., 2014; Battiato and Diserens, 2017). Fig. 5b illustrates the interaction between the ballast weights and tire inflation pressure. It indicates that the slip decreases with decrease in inflation pressure and increase in the ballast weight. Scrutinizing Fig. $5 \mathrm{~b}$ reveals that the slip decreases with decreasing inflation pressure and increasing ballast weight so that by applying the inflation pressure of $170 \mathrm{kPa}$ and ballast weight of $300 \mathrm{~kg}$, a slip value of less than $10 \%$ can be achieved, while applying the inflation pressure of $230 \mathrm{kPa}$ and without ballast weight, the slip level was higher than $20 \%$. Reducing the slip by raising the ballast weight and decreasing the inflation pressure is because both factors increased the wheel-soil contact area and with the improvement of soil and wheel conflict, the tire slip was reduced (Muhsin, 2010; Battiato and Diserens, 2013; Damanauskas and Janulevicius, 2015).

Fig. $6 a$ shows that the increase of ballast weight leads to an increase in the rolling resistance, since the wheel load plays a major role in increasing the wheel's rolling resistance. Such a process has also been reported by other researchers (Taghavifar and Mardani 2013; Taghavifar and Mardani

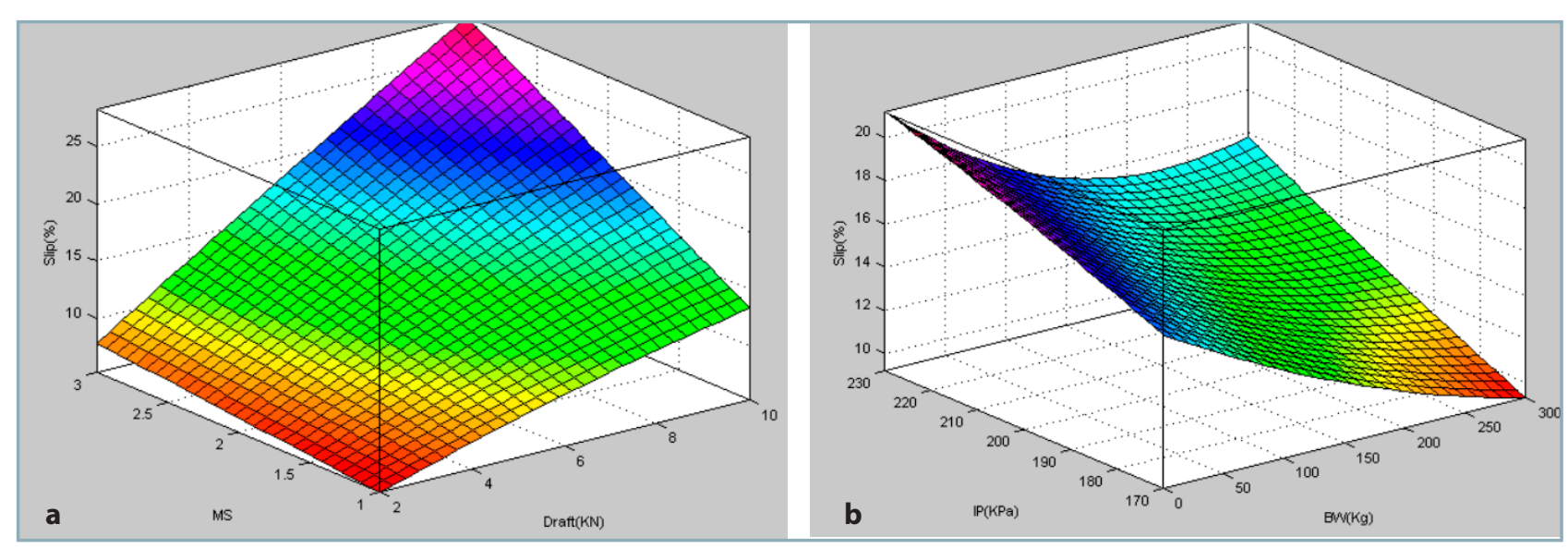

Fig. 5 3D surface curves of slip by interactions of input parameters; (a) interaction between MS and draft, (b) interaction IP and BW

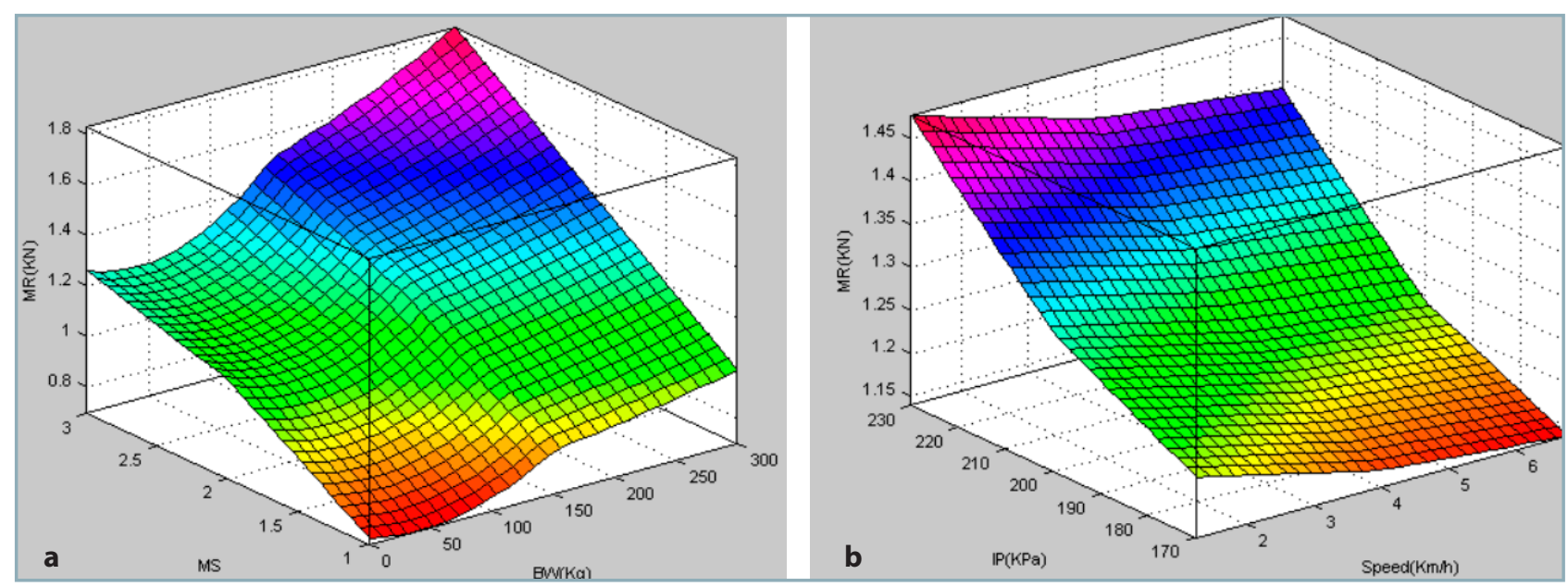

Fig. 6 3D surface curves of MR by interactions of input parameters; (a) interaction between MS and BW, (b) interaction IP and speed 
2014). In Fig. 6b, increasing travel speed reduced the rolling resistance, which can be attributed to the fact that, at lower speeds, the wheel loading time on the soil increases, resulting in the increased tire sinkage in soil and soil deformation. The energy used to deform the soil increases rolling resistance, so the movement speed can be increased to prevent energy loss in the soil. The type of tractor driving system has a significant effect on the reduction of rolling resistance. As shown in Fig. $6 a$, the four-wheel-drive mode had a lower rolling resistance in contrast to two the other observed modes. This result can be explained by the fact that drive wheel contact area in fourwheel-drive mode is doubled in comparison to two other modes, and increase in the contact area of wheels with the soil reduced the rolling resistance. The influence of contact area of the wheel with the soil has been investigated by several researchers who reported similar results (Damanauskas et al., 2015). In regards to this, Botta et al. (2012) compared the rolling resistance of a four-wheel drive and two-wheel drive tractor. Although the four-wheel-drive tractor had a higher weight, it had a lower rolling resistance than a two-wheeldrive tractor. As shown in Fig. $6 \mathrm{~b}$, reduction of tire inflation pressure reduces the rolling resistance. The influence of inflation pressure on the rolling resistance is explained by the contact area of the tire with the soil.

\section{Conclusion}

- In contrast to the stepwise regression model, the ANFIS model showed a higher performance in predicting slip and rolling resistance.

- Applying the four-wheel-drive mode without the use of ballast weights and reduction of the inflation pressure resulted in the lower level of slip and rolling resistance. Therefore, in the four-wheel-drive mode, there is no need for increasing the ballast weights and decreasing the inflation pressure. This solution is superior, since any increase in weight and reduction in pressure cause damage to tires and reduce their lifespan.

- It was found that draft, tractor driving system, inflation pressure, ballast weights, and tractor travel speed have the greatest effect on the slip, in the presented order. Furthermore, the results showed that the tractor driving system, ballast weight, inflation pressure, and tractor travel speed also have a significant impact on the rolling resistance, in the presented order.

- Ballast weight showed both advantages and disadvantages for traction performance, because by increasing the ballast weight, slip decreases and rolling resistance increases. Ballast weight should increase when the tractor slip is high so that the advantages of slip reduction can compensate for the disadvantages of increasing the rolling resistance.

\section{References}

ABBASPOUR-GILANDEH, Y. - HAGHIGHAT-SHISHVAN, S. 2011. Extended octagonal ring transducers for measurement of tractorimplement forces. In Instruments and Experimental Techniques, vol. 54, no. 1, pp. 136-140.

BARBOSA, L. A. P. - MAGALHAES, P. S. G. 2015. Tire tread pattern design trigger on the stress distribution over rigid surfaces and soil compaction. In Journal of Terramechanics, vol. 58, pp. 27-38.
BATTIATO, A. - DISERENS, E. 2013. Influence of tyre inflation pressure and wheel load on the traction performance of a $65 \mathrm{~kW}$ MFWD tractor on a cohesive soil. In Journal of Agricultural science, vol. 5, no. 8, pp. 197-215.

BATTIATO, A. - DISERENS, E. 2017. Tractor traction performance simulation on differently textured soils and validation: a basic study to make traction and energy requirements accessible to the practice. In Soil and Tillage Research, vol. 166, pp. 18-32.

BATTIATO, A. - DISERENS, E. - LALOUI, L. - SARTORI, L. 2013. A mechanistic approach to topsoil damage due to slip of tractor tyres. In Journal of Agricultural Science and Applications, vol. 2, no. 3, pp. 160-168.

BOTTA, G. - TOLON-BECERRA, A. - TOURN, M. - LASTRA-BRAVO, X. - RIVERO, D. 2012. Agricultural traffic: Motion resistance and soil compaction in relation to tractor design and different soil conditions. In Soil and Tillage Research, vol. 120, pp. 92-98.

BUCKLEY, J. J - HAYASHI, Y. 1994. Fuzzy neural networks: A survey. In Fuzzy Sets and Systems, vol. 66, no. 1, pp. 1-13.

CARMAN, K. 2008. Prediction of soil compaction under pneumatic tires a using fuzzy logic approach. In Journal of Terramechanics, vol. 45 , no. 4, pp. 103-105.

DAMANAUSKAS, V. - JANULEVICIUS, A. 2015. Differences in tractor performance parameters between single-wheel 4WD and dual-wheel 2WD driving systems. In Journal of Terramechanics, vol. 60, pp. 63-73.

DAMANAUSKAS, V. - JANULEVICIUS, A. - PUPINIS, G. 2015. Influence of extra weight and tire pressure on fuel consumption at normal tractor slippage. In Journal of Agricultural Science, vol. 7, no. 2, pp. 55-67.

ELWALEED, A.K. - YAHYA, A. - ZOHADIE, M. - AHMAD, D. - KHEIRALLA, A. F. 2006. Effect of inflation pressure on motion resistance ratio of a high-lug agricultural tyre. In Journal of Terramechanics, vol. 43, no. 2, pp. 69-84.

GHADERNEJAD, K. - SHAHGHOLI, G. - MARDANI, A. - GHAFOURI CHIYANEH, H. 2018. Prediction effect of farmyard manure, multiple passes and moisture content on clay soil compaction using adaptive neuro-fuzzy inference system. In Journal of Terramechanics, vol. 77, pp. 49-57.

JANULEVICIUS, A. - DAMANAUSKAS, V. - PUPINIS, G. 2018. Effect of variations in front wheels driving lead on performance of a farm tractor with mechanical front-wheel-drive. In Journal of Terramechanics, vol. 77, pp. 23-30.

LACOUR, S. - BURGUN, C. - PERILHON, C. - DESCOMBES, G. - DOYEN, V. 2014. A model to assess tractor operational efficiency from bench test data. In Journal of Terramechanics, vol. 54, pp. 1-18.

MOITZI, G. - HAAS, M. - WAGENTRISTL, H. - BOXBERGER, J. GRONAUER, A. 2013. Energy consumption in cultivating and ploughing with traction improvement system and consideration of the rear furrow wheel-load in ploughing. In Soil and Tillage Research, vol. 134, pp. 56-60.

MOINFAR, A. M. - SHAHGHOLI, G. 2018. Dimensional analysis of the tractor tractive efficiency parameters. In Acta Technologica Agriculurae, vol. 21, no. 3, pp. 94-99.

MUHSIN, S. J. 2010. Studying the power losses of two and four wheel drive tractors (2WD and 4WD) of Massy Ferguson 2680. In Journal of Basrah Research Sciences, vol. 36, no. 6, pp. 59-66.

TAGHAVIFAR, H. - MARDANI, A. 2013. Investigating the effect of velocity, wheel load and inflation pressure on rolling resistance of radial ply tire. In Journal of Terramechanics, vol. 50, no. 2, pp. 99-106. TAGHAVIFAR, H. - MARDANI, A. 2014. On the modeling of energy efficiency indices of agricultural tractor driving wheels applying adaptive neuro-fuzzy inference system. In Journal of Terramechanics, vol. 56, pp. 37-47.

WANG, L. X. 1997. A Course in Fuzzy Systems and Control. PrenticeHall Inc. 